\title{
Exogenous IL-10 induces corneal transplantation immune tolerance by a mechanism associated with the altered Th1/Th2 cytokine ratio and the increased expression of TGF- $\beta$
}

\author{
BING LI $^{1}$, LIHUA TIAN $^{1}$, YUMEI DIAO $^{1}$, XUE LI $^{1}$, LIYING ZHAO $^{1}$ and XUEFENG WANG ${ }^{2}$ \\ Departments of ${ }^{1}$ Ophthalmology and ${ }^{2}$ Otolaryngology, First Hospital of Liaoning Medical College, \\ Jinzhou, Liaoning 121001, P.R. China
}

Received July 3, 2013; Accepted March 4, 2014

DOI: $10.3892 / \mathrm{mmr} .2014 .2073$

\begin{abstract}
The aim of the present study was to examine the effect of exogenous IL-10 transfected rat dendritic cells (DCs) in corneal allografts. Rat lymphocyte separation medium and a cytokine induction method was used to extract and culture precursor cells of rat bone marrow-derived dendritic cells. A corneal transplant model was established, with Sprague-Dawley (SD) rats as the recipients and Wistar rats as the donors. Flow cytometry (FCM) was used to detect the expression of CD83, which indicates a mature dendritic cell, and a specific cell surface stimulatory molecule CD86. Western blot analysis was used to detect interleukin (IL)-10 protein expression and RT-PCR was used to detect cytokine IL-10, IL-2 and TGF- $\beta$ mRNA expression in each group. Compared with the other groups, the survival time of corneal grafts in the IL-10-green fluorescent protein (GFP)-DC group was significantly prolonged and H\&E staining demonstrated mild graft edema and inflammatory cell infiltration. There was a high expression of IL-10 and a low expression of the surface antigens, CD83 and CD86, with a lower proliferation of $\mathrm{T}$ lymphocytes in the IL-10-GFP-DC group. The expression of IL-10 and TGF- $\beta$ in the IL-10-GFP-DC group was higher than that in the other groups, while the expression of IL-2 was lower. The transfection of the IL-10 gene inhibited dendritic cell maturation. IL-10 gene-modified immature dendritic cells (imDC) were able to inhibit corneal allograft rejection and induce immune tolerance to prolong the survival time of the corneal graft. The Th1/Th2 deviation and the high expression of TGF- $\beta$ may lead to immune tolerance.
\end{abstract}

Correspondence to: Dr Xuefeng Wang, Department of Otolaryngology, First Hospital of Liaoning Medical College, No. 2 Wuduan, Renmin Street, Jinzhou, Liaoning 121001, P.R. China E-mail: wangxuefeng1965@163.com

Key words: dendritic cells, IL-10, gene transfection, corneal transplantation, immune tolerance, cytokine

\section{Introduction}

Corneal transplantation is an effective treatment for corneal blindness $(1,2)$. However, rejection following transplantation is a major cause of its failure (3-6). Corneal transplant rejection is caused by $\mathrm{T}$ lymphocyte-mediated delayed-type hypersensitivity (DTH). $\mathrm{CD}^{+} \mathrm{T}$ cells are important in DTH (7-9). Following activation, $\mathrm{CD}^{+} \mathrm{T}$ cells differentiate into subgroups of Th1 and Th2. Th1 secretes interleukin (IL)-2, interferon (IFN) $-\gamma$ and other cytokines to mediate DTH. Th2 secretes IL-10 and IL-4 to mediate immune tolerance. Under normal circumstances, Th1/Th2 remains at a relatively stable level to maintain normal humoral and cellular immune function (10). TGF- $\beta$ is a cytokine which exists in the cornea, aqueous humor and all tissues and organs in the form of a polypeptide. It is a negative regulator of the immune and inflammatory response to suppress the activation of T cells (11). TGF- $\beta$ is also involved in anterior chamber-associated immune deviation (ACAID) to delay DC maturation and induce allograft immune tolerance (12-15).

Dendritic cells (DCs) are the most proficient antigen presenting cells (APCs), which have been identified thus far. Immature dendritic cells (imDC) are important for the induction of immune tolerance $(16,17)$. IL-10 is a cytokine synthesis inhibitory factor (18), acting on APCs to reduce the expression of MHC class I molecules, co-stimulatory molecules and adhesion molecules.

In the present study, an adenovirus carrying the IL-10 gene was used to transfect imDC in order to study alterations in biological characteristics following transfection. A rat cornea transplantation animal model was used to investigate the IL-10 gene-modified, DC-induced corneal transplantation immunotolerance, in order to provide evidence for the prevention and treatment of corneal graft rejection.

\section{Materials and methods}

Animals. Healthy, male and female, 6-8-week-old Wistar rats, weighing between 200-250 g, were purchased from the Experiment Animal Center of China Medical University (Shenyang, Liaoning, China). Healthy, male and female, 6-8-week-old Sprague-Dawley rats, weighing between 
200-250 g were purchased from the Experiment Animal Center of Liaoning Medical College (Jinzhou, Liaoning, China). The study was approved by the Ethics Committee of Liaoning Medical College (Jinzhou, China).

Reagent. The adenovirus for IL-10 gene overexpression (IL-10-GFP-adenovirus) and the adenovirus for the green fluorescent protein gene (GFP-adenovirus) were purchased from Shanghai Genechem Chemical Technology Co., Ltd. (Shanghai, China). RPMI-1640 medium was obtained from Gibco-BRL (Carlsbad, CA, USA) and fetal bovine serum was purchased from Hyclone (Logan, UT, USA). Recombinant rat granulocyte-macrophage colony stimulating factor and recombinant rat IL-4 were obtained from PeproTech (Rocky Hill, NJ, USA). Mitomycin C was obtained from TBD Biotech (Tianjin, China). The MTT cell proliferation kit was purchased from Pik-day Institute of Biotechnology (Shenzhen, Guangdong, China). The anti-rat CD83 monoclonal antibody, mouse monoclonal $\mathrm{IgG}_{2 \mathrm{a}} \mathrm{PE}$ and fluorescein isothiocyanate (FITC)-labeled anti-rat CD86 monoclonal antibody were obtained from Santa Cruz Biotechnology, Inc. (Santa Cruz, CA, USA).

Culture and transfection of rat bone marrow-derived dendritic cells. DCs were divided into three groups, including the DC group, the GFP-12-DC group and the IL-10-GFP-12-DC group. The DC group was cultured in the original condition for 12 days. The GFP-12-DC group was transfected with the GFP-adenovirus with a titer of $10^{7} \mathrm{PUF} / \mathrm{ml}$. The IL-10-GFP12-DC group was transfected with the IL-10-GFP-adenovirus with a titer of $10^{7} \mathrm{PUF} / \mathrm{ml}$. The transfection was performed after cells were cultured in the original condition for 6 days, followed by a 6 -day culture.

Western blotting. Following the measurement of protein concentration, the protein was separated by SDS-PAGE electrophoresis. Gene Tools software was used to systematically analyze the gray value of the target strip. Rabbit anti-rat IL-10 monoclonal antibody (Sangon; Shanghai, China) and goat anti-rabbit monoclonal antibody (Sangon) were used.

Flow cytometry (FCM). IL-10-GFP-12-DC, GFP-12-DC and 12-DC were collected, respectively, to adjust the cell concentration to $1 \times 10^{7} / \mathrm{ml}$. In order to detect the surface antigen CD83, $25 \mu \mathrm{l}$ of CD83 antibody and $12.5 \mu \mathrm{l}$ of $\mathrm{IgG}_{2 \mathrm{~A}}$-PEs were added in each group. Following mixing, the solution was incubated at $4^{\circ} \mathrm{C}$ for $30 \mathrm{~min}$. The negative control group with the antibody only was incubated and washed with PBS and then fixed with $1 \%$ paraformaldehyde. In order to detect the surface antigen CD86, $5 \mu \mathrm{l}$ of FITC-anti-CD86 was added to the experiment groups. The solution was incubated at $4^{\circ} \mathrm{C}$ for $30 \mathrm{~min}$. The negative control group of the antibody only was incubated and washed with PBS, then fixed with $1 \%$ paraformaldehyde. FCM was applied for cell phenotype analysis.

MTT. Following incubation, $10 \mu \mathrm{l}$ of MTT was added in each well and the solution was incubated for a further $4 \mathrm{~h}$. Formazan lysate $(100 \mu \mathrm{l})$ was added to each well and incubated until the formazan completely dissolved under the optical microscope. The absorbance optical density (OD) value was measured at
$570 \mathrm{~nm}$ by a microplate reader. The result value was obtained from the mean value of three holes.

Corneal transplantation experiments. In accordance with previous studies (19), the corneal transplant model, with SD rats as the recipients and Wistar rats as the donors, was established. The diameter of the graft was $3.5 \mathrm{~mm}$ and the graft beds were $3.0 \mathrm{~mm}$. The recipient SD rats were randomly divided into four groups and intravenously injected with PBS $(1 \mathrm{ml}), \mathrm{DC}\left(2 \times 10^{6} / \mathrm{ml}\right)$, GFP-DC $\left(2 \times 10^{6} / \mathrm{ml}\right)$ or IL-10-GFP-DC $\left(2 \times 10^{6} / \mathrm{ml}\right)$, respectively, 3 days prior to surgery. Corneal transplantation was performed 3 days later. The transfection was performed after cells were cultured in the original condition for 6 days, followed by a $48 \mathrm{~h}$ culture. In the control group, the DC cells were cultured in the original condition for 6 days, followed by a $48 \mathrm{~h}$ culture.

Histological and pathological examination. On the 14th day after surgery, four rats in each group were randomly selected and normal SD rats were used as the negative control. The rats were sacrificed by excessive anesthesia and full enucleation was performed. The sample was fixed with $10 \%$ formalin and normally embedded by paraffin. The sample was sliced to $5 \mu \mathrm{m}$ for H\&E staining.

$R T-P C R$. Total RNA was extracted and RNA purity was determined by A260/A280 ratio. The cDNA was synthesized by a reverse transcription reaction with a reaction system of $10 \mu 1$, according to the manufacturer's instructions of the RT-PCR kit (Takara Bio, Inc., Shiga, Japan). The primers for the PCR reaction were synthesized by Takara Biotechnology Co., Ltd. (Dalian, Liaoning, China) and the primer sequences are shown in Table I. PCR was completed following denaturation, annealing, extension and a total of 36 cycles. For electrophoresis and imaging of PCR, $10 \mu \mathrm{l}$ of the PCR reaction product was analyzed by electrophoresis.

Statistical analysis. Statistical analysis software SPSS 17.0 was used for data processing. All data are expressed as the mean \pm standard deviation and analyzed by one-way ANOVA. $\mathrm{P}<0.05$ was considered to indicate a statistically significant difference.

\section{Results}

Expression of the IL-10 protein. In order to determine the expression of IL-10, fluorescence detection and western blot analysis were performed. A weak GFP expression was observed by fluorescence detection and by using western blot analysis, a characteristic strip was shown and its size was consistent with the IL-10 fusion protein ( $48 \mathrm{kDa})$. The molecular weight of rat $\beta$-actin is $42 \mathrm{kDa}$. The expression level was evaluated as the gray value ratio of gel electrophoresis with the target gene and the internal control gene $\beta$-actin, as shown in Fig. 1A and Table II. These results suggest that IL-10 was expressed in DCs via the adenoviral vector.

Determination of the DC phenotype. To determine the effects of IL-10 transfection on DCs, the expression of the cell surface molecules CD83 and CD86 were detected by FCM. 
Table I. Primers used in the present study.

\begin{tabular}{llll}
\hline Gene & Primer & Sequence & Length (bp) \\
\hline IL-2 & Forward & Reverse & 5'-GCGCACCCACTTCAAGCCCT-3' \\
IL-10 & Forward & 5'-CCACCACAGTTGCTGGCTCA-3' & 350 \\
& Reverse & 5'-ACTGCTATGTTGCCTGCTCTTACT-3' \\
TGF- $\beta 1$ & Forward & 5'-GAATTCAAATGCTCCTTGATTTCT-3' & 318 \\
$\beta$-actin & Reverse & 5'-AATACGTCAGACATTCGGGAAGCA-3' \\
& Forward & 5'-GTCAATGTACAGCTGCCGTACACA-3' & 498 \\
\hline
\end{tabular}

IL, interleukin; TGF- $\beta 1$, transforming growth factor- $\beta 1$.

Table II. Gray value ratio of IL-10 fusion protein to $\beta$-actin (mean \pm standard deviation).

\begin{tabular}{lc}
\hline Group & Ratio \\
\hline 12-DC & $0.097 \pm 0.021$ \\
GFP-12-DC & $0.127 \pm 0.023$ \\
IL-10-GFP-12-DC & $1.023 \pm 0.045^{\mathrm{a}, \mathrm{b}}$ \\
\hline
\end{tabular}

${ }^{\mathrm{a}} \mathrm{P}<0.01$, compared with the $12-\mathrm{DC}$ group; ${ }^{\mathrm{b}} \mathrm{P}<0.01$, compared with the GFP-12-DC group. DC, dendritic cell; GFP, green fluorescent protein; IL-10, interleukin-10.

The expression of the surface molecules, CD83 and CD86, in the IL-10-GFP-12-DC group was $\sim 17$ and 20\%, respectively. The expression level was low, compared with the GFP-12-DC group (44 and 42\%) and the 12-DC group (45 and 48\%), as shown in Fig. 2. These results suggest that IL-10 transfection inhibits the maturation of DCs.

MTT cell proliferation assay. In order to determine the effects of DCs on the proliferation of allogeneic T lymphocytes, MTT cell proliferation assays were performed. By MTT assay, the DC stimulated allogeneic lymphocyte proliferation of different concentrations in each group was determined. The OD value of mixed cells and $\mathrm{T}$ cells in each group and RPMI-1640 in the control group was measured by a microplate reader. The OD value was calculated using the following formula: OD value $=$ OD value of mixed cells - OD value of RPMI-1640 in the control group - OD value of T cells. The results were repeated three times in each group independently, as shown in Table III. These results suggest that IL-10 gene transfection inhibits the ability of DCs to stimulate the proliferation of allogeneic T lymphocytes.

Histological examination of the corneal graft. To determine pathological changes in the corneal graft, tissue biopsy $\mathrm{H} \& \mathrm{E}$ staining was performed. In the PBS group, 14 days after surgery, there was edema in the corneal grafts, with visible inflammatory cell infiltration, neovascularization and disorganized layers of tissue. In the GFP-DC group and the DC group, there was mild edema, with visible inflammatory cell infiltra- tion, a small amount of neovascularization and a neat layered structure. In the IL-10-GFP-DC group, there was mild edema of grafts, with few inflammatory cell infiltration and neovascularization and the layers were organized in a neat structure, as shown in Fig. 3. The survival time of corneal grafts are shown in Table IV. These results suggest that the expression of IL-10-GFP-DC reduces the inflammatory response of the corneal graft and significantly prolongs the corneal graft survival time.

RT-PCR of cytokines IL-2, IL-10 and transforming growth factor (TGF)- $\beta 1$. To understand the immunomodulatory mechanisms of the DCs transfected with the IL-10 gene, RT-PCR was performed to detect the expression of IL-2, IL-10 and TGF- $\beta 1$ in the surgical cornea. In total, six rats were randomly selected for sample collection 14 days after surgery. The cornea of normal SD rats was the negative control. The $500 \mathrm{bp}$ was a reference standard for the levels of target gene expression to measure the gray value of the target gene and $\beta$-actin in each group. The results are expressed as the ratio of the target gene value and $\beta$-actin value. The determination of IL-2, IL-10 and TGF- $\beta 1$ gene expression by RT-PCR was independently repeated three times. The results of the target gene electrophoresis are shown in Fig. 1B. The gray value ratio is shown in Table $\mathrm{V}$. These results suggest that the IL-2 level was decreased while the levels of IL-10 and TGF- $\beta 1$ were increased in the IL-10-GFP-DC group, when compared with the other groups.

\section{Discussion}

ImDCs are one of the tools used to induce transplantation tolerance (20). The investigation of transplantation immune tolerance with the use of DCs has become a major focus of study with the aim of maintaining DCs in an immature state and weakening their antigen-presenting function. It has been reported that using $1 \alpha, 25$-dihydroxyvitamin $\mathrm{D}_{3}\left[1,25(\mathrm{OH})_{2} \mathrm{D}_{3}\right]$, receptor immune tolerance may be induced in cytokine-induced DCs or genetically modified DCs in vitro (21-26). It has been widely demonstrated that inducing or modifying DCs in the early culture, may alter their biological characteristics (20-22).

In the present study, the solution of IL-10 gene transfected DCs was injected through the tail vein into recipient rats. 
Table III. OD value in MTT cell proliferation assay.

\begin{tabular}{lcc}
\hline Group & $\begin{array}{c}\text { Number of stimulating cells/ } \\
\text { number of reacting cells* } \\
(1: 10)\end{array}$ & $\begin{array}{c}\text { Number of stimulating cells/ } \\
\text { number of reacting cells } \\
(1: 20)\end{array}$ \\
\hline 12-DC & $0.497 \pm 0.025$ & $0.567 \pm 0.102$ \\
GFP-12-DC & $0.463 \pm 0.041$ & $0.543 \pm 0.070$ \\
IL-10-GFP-12-DC & $0.160 \pm 0.036^{\mathrm{a}, \mathrm{b}}$ & $0.230 \pm 0.053^{\mathrm{a}, \mathrm{b}}$ \\
\hline
\end{tabular}

*Stimulating cells and reacting cells were mixed with different ratios (1:10 or 1:20) when MTT was performed; ${ }^{\mathrm{P}}<0.01$, compared with the 12-DC group; ${ }^{\circ} \mathrm{P}<0.01$, compared with the GFP-12-DC group. OD, optical density; DC, dendritic cell; GFP, green fluorescent protein; IL-10, interleukin-10.

Table IV. Survival time of the corneal graft in each group.

\begin{tabular}{lccc}
\hline Group & Sample (n) & Survival time (days) & Mean \pm SD \\
\hline PBS & 7 & $9,11,10,8,13,12,9$ & $10.86 \pm 0.60$ \\
GFP-DC & 6 & $21,18,23,17,19,19$ & $19.50 \pm 0.89^{\mathrm{a}}$ \\
8-DC & 6 & $20,19,22,18,20,18$ & $19.67 \pm 1.37^{\mathrm{a}}$ \\
IL-10-GFP-DC & 6 & $23,24,27,25,28,26$ & $25.50 \pm 0.76^{\mathrm{a}, \mathrm{b}, \mathrm{c}}$ \\
\hline
\end{tabular}

${ }^{\mathrm{a}} \mathrm{P}<0.01$, compared with the PBS group; ${ }^{\mathrm{b}} \mathrm{P}<0.01$, compared with the GFP-DC group; ${ }^{\mathrm{c}} \mathrm{P}<0.01$, compared with the DC group. DC, dendritic cell; GFP, green fluorescent protein; IL-10, interleukin-10; TGF- $\beta 1$, transforming growth factor- $\beta 1$.

Table V. Cytokine expression in the allogeneic corneal grafts in each group, 14 days after transplantation.

\begin{tabular}{llll}
\hline Group & \multicolumn{1}{c}{ IL-2 } & IL-10 & TGF- $\beta 1$ \\
\hline Negative control & $0.001 \pm 0.000$ & $0.227 \pm 0.023$ & $0.141 \pm 0.010$ \\
PBS & $0.423 \pm 0.113^{\mathrm{a}}$ & $0.352 \pm 0.010^{\mathrm{a}}$ & $0.203 \pm 0.011^{\mathrm{a}}$ \\
GFP-DC & $0.379 \pm 0.201^{\mathrm{a}, \mathrm{b}}$ & $0.582 \pm 0.010^{\mathrm{a}, \mathrm{b}}$ & $0.411 \pm 0.010^{\mathrm{a}, \mathrm{b}}$ \\
DC & $0.387 \pm 0.320^{\mathrm{a}, \mathrm{b}}$ & $0.577 \pm 0.021^{\mathrm{a}, \mathrm{b}}$ & $0.407 \pm 0.021^{\mathrm{a}, \mathrm{b}}$ \\
IL-10-GFP-DC & $0.109 \pm 0.162^{\mathrm{a}, \mathrm{b}, \mathrm{c}, \mathrm{d}}$ & $0.986 \pm 0.015^{\mathrm{a}, \mathrm{b}, \mathrm{c}, \mathrm{d}}$ & $0.702 \pm 0.011^{\mathrm{a}, \mathrm{b}, \mathrm{c}, \mathrm{d}}$ \\
\hline
\end{tabular}

${ }^{\mathrm{a}} \mathrm{P}<0.05$, compared with the negative control group; ${ }^{\mathrm{b}} \mathrm{P}<0.05$, compared with the $\mathrm{PBS}$ group; ${ }^{\mathrm{c}} \mathrm{P}<0.01$, compared with the GFP-DC group; ${ }^{\mathrm{d}} \mathrm{P}<0.01$, compared with the DC group. DC, dendritic cell; GFP, green fluorescent protein; IL-10, interleukin- 10 ; TGF- $\beta 1$, transforming growth factor- $\beta 1$.

A

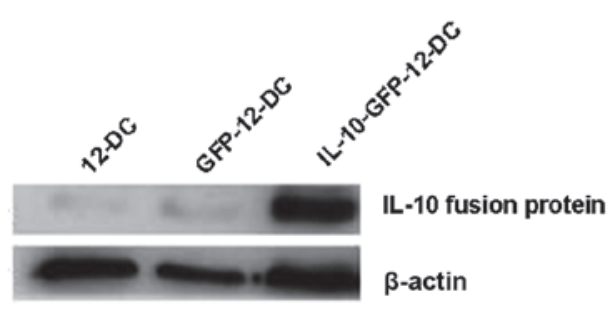

B

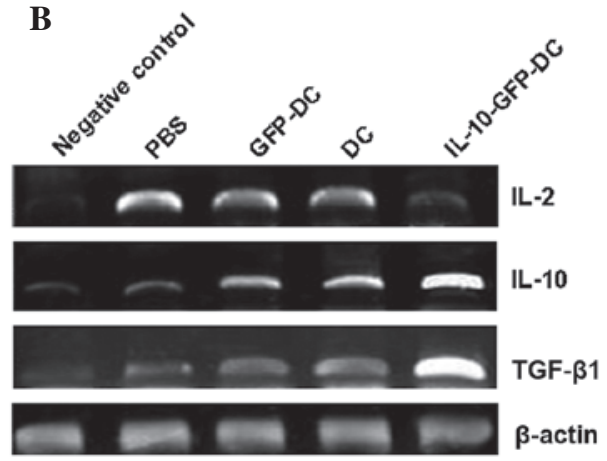

Figure 1. Determination of the expression levels of protein or mRNA. (A) Western blot analysis of the IL-10 protein. The total proteins were extracted and separated by SDS-PAGE electrophoresis. Rabbit anti-mouse IL-10 monoclonal antibody and goat anti-rabbit monoclonal antibody were used. A high-level band of $48 \mathrm{kDa}$ was identified in the IL-10-GFP-adenovirus group. (B) RT-PCR determination of IL-2, IL-10 and TGF- $\beta 1$ in corneas. Following RNA extraction and RT-PCR, $10 \mu \mathrm{l}$ of PCR product was analyzed by electrophoresis. The expected sizes of the amplified specific products were 350 bp for IL-2, 318 bp for IL-10, $498 \mathrm{bp}$ for TGF- $\beta 1$ and $150 \mathrm{bp}$ for $\beta$-actin. IL, interleukin; TGF- $\beta 1$, transforming growth factor- $\beta 1$; GFP, green fluorescent protein. 
A

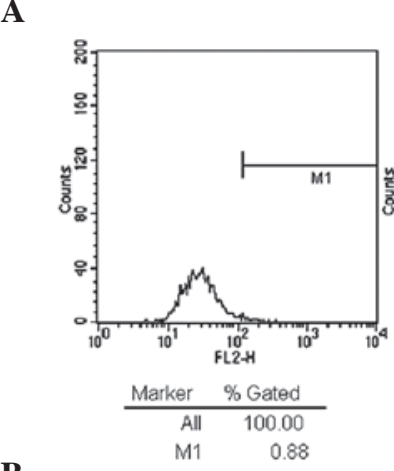

$\mathbf{B}$
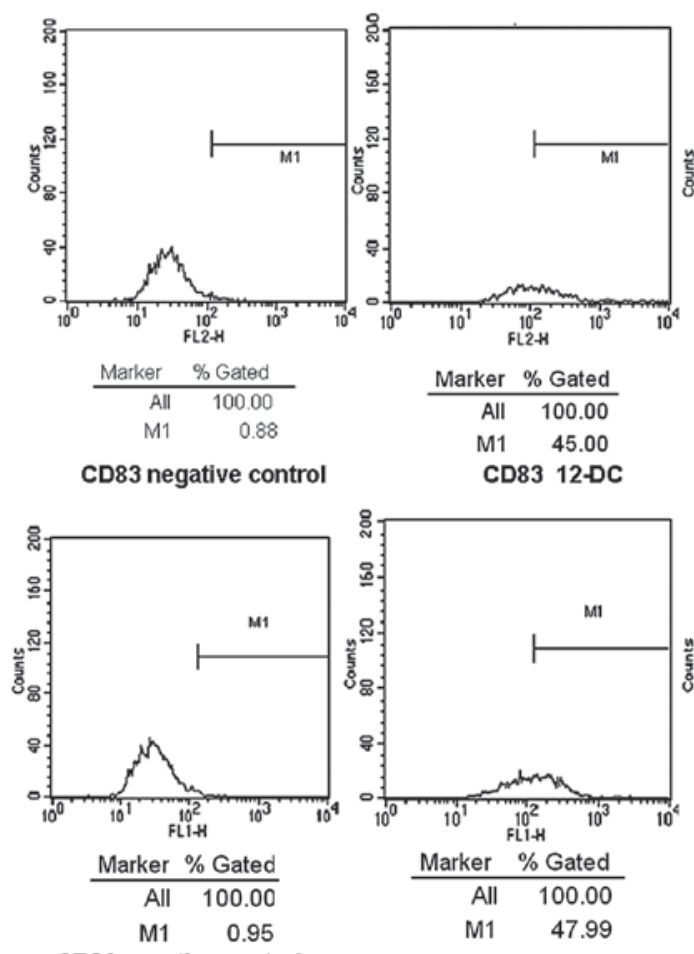

CD86 negative control

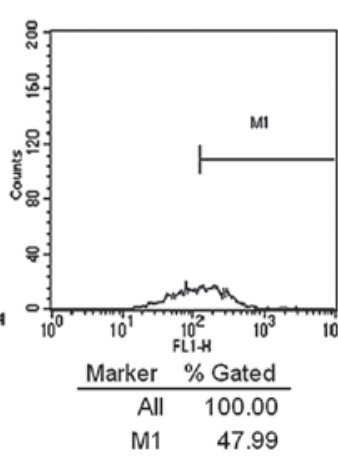

CD86 12-DC
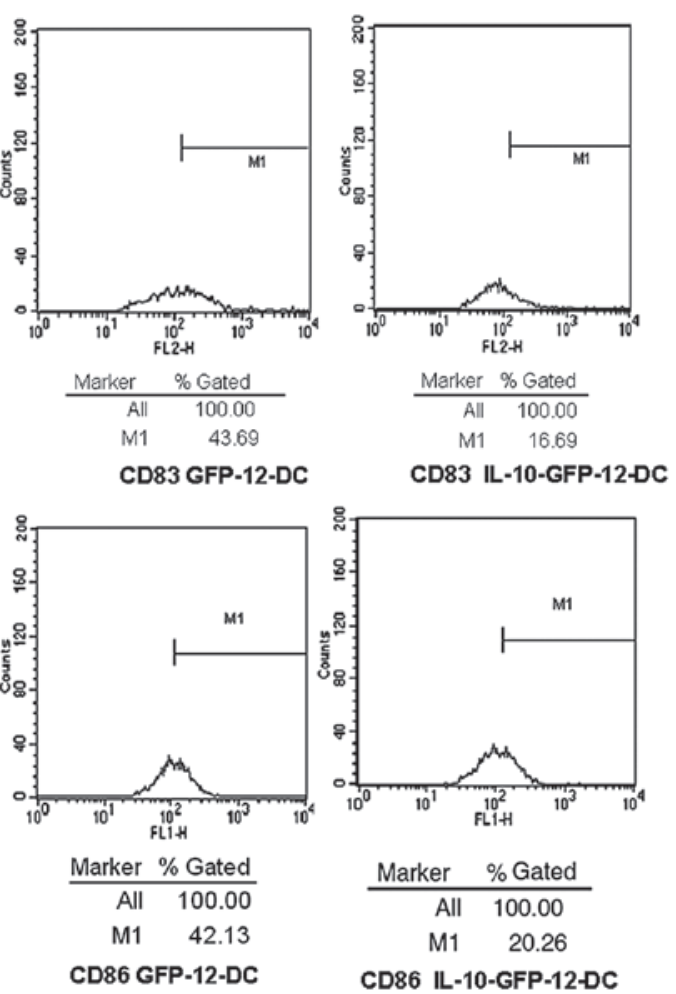

Figure 2. Expression of cell surface molecules, CD83 and CD86, of DCs. The cell concentration was adjusted to 1x107/ml. Anti-rat CD83 monoclonal antibody, mouse monoclonal $\mathrm{IgG}_{2 \mathrm{a}}$-PE and FITC-labeled anti-rat CD86 monoclonal antibody were used. The expression of surface molecules, CD83 and CD86, in the IL-10-GFP-12-DC group was $\sim 17$ and 20\%, respectively. (A) Cell surface CD83 expression in each group detected by FCM; (B) cell surface CD86 expression in each group detected by FCM. DCs, dendritic cells; FITC, fluorescein isothiocyanate; FCM, flow cytometry.

A

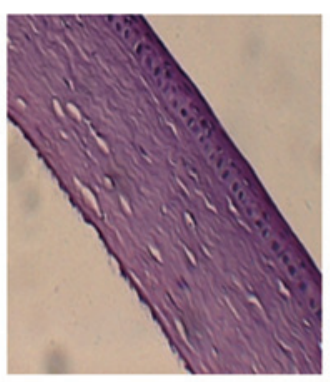

B

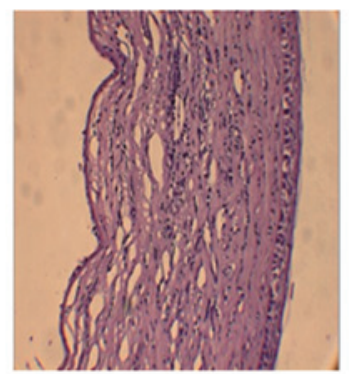

C

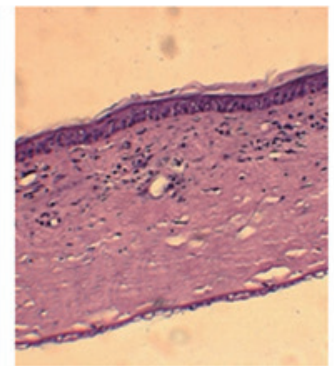

D

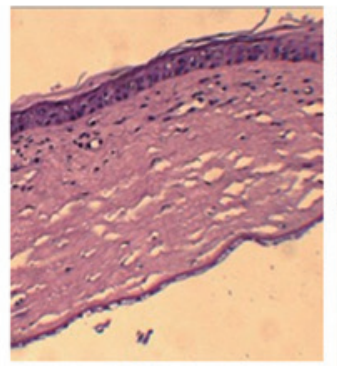

$\mathbf{E}$

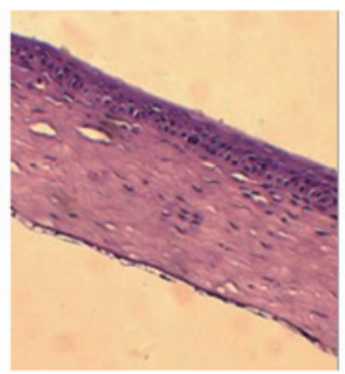

Figure 3. Histological and pathological examination. (A) In the negative control group (magnification, x200; H\&E), corneal layers were in a neat structure without edema, inflammatory cell infiltration and neovascularization. (B) PBS group (magnification, x200; H\&E), there was visible corneal edema with inflammatory cell infiltration, neovascularization and disorganized layers of tissue. (C) GFP-DC group (magnification, x200; H\&E) corneal layers were in a neat structure with stromal edema and there was a small amount of inflammatory cell infiltration and a small amount of neovascularization. (D) DC group (magnification, x200; H\&E), corneal layers were in a neat structure with visible stromal edema and there was a small amount of inflammatory cell infiltration and neovascularization. (E) IL-10-GFP-DC group (magnification, x200; H\&E), corneal layers were in a neat structure with mild edema and a small amount of inflammatory cell infiltration. DC, dendritic cell; GFP, green fluorescent protein; IL-10, interleukin-10.

After 3 days, a corneal transplant was performed and it was demonstrated that in the IL-10-GFP-DC group, the survival time of the corneal graft was significantly prolonged. This may result from the growing maturity of DCs in the body with time. While in DCs with the IL-10 gene, the sustained expression of IL-10 inhibited DC maturation and, therefore, the survival time of the corneal graft was significantly prolonged.

To further investigate the immune tolerance mechanism of the IL-10 gene modified rat DC induced corneal transplan- tation, RT-PCR was used to detect IL-2, IL-10 and TGF- $\beta 1$ expression in the cornea of the negative control group and each group 14 days after surgery. It was demonstrated that in the IL-10-GFP-DC group, IL-10 expression was increased (Th2 cytokines) and IL-2 expression was decreased (Th1 cytokines), resulting in Th1/Th2 imbalance. While in the IL-10-GFP-DC group, TGF- $\beta$ expression was significantly higher than that in the other groups. It is hypothesized that IL-10-GFP-DC induced the secretion and activation of TGF- $\beta$, TGF- $\beta$ inhibited T-cell activation and proliferation, and TGF- $\beta$ and IL-10 
synergistically maintain the immature state of DCs for their immunosuppression.

Corneal transplant rejection is the main reason for graft failure. The induction of immune tolerance is an important issue for corneal transplant success. In the present study, IL-10 gene-modified DCs significantly prolonged the survival time of corneal transplantation grafts, indicating IL-10 gene-modified DCs induced immune tolerance and may be an effective method to establish allograft immune tolerance. Due to the limited survival time of allogeneic DCs in the donor, newborn DCs quickly mature through antigen stimulation, resulting in a limited survival time of corneal grafts in the experimental group. This indicates that the IL-10 gene modified DCs are limited in their ability to induce corneal transplantation immune tolerance and that transplant rejection is a complex multi-channel immune response. Therefore, immune tolerance may be induced by multi-channel and co-regulation, in order to establish a lasting and effective immune resistance.

\section{Acknowledgements}

This study was supported by a grant from the Key Laboratory Project of the Department of Education, Liaoning Province (no. LS2010103).

\section{References}

1. Oliva MS, Schottman T and Gulati M: Turning the tide of corneal blindness. Indian J Ophthalmol 60: 423-427, 2012.

2. Tan DT, Dart JK, Holland EJ and Kinoshita S: Corneal transplantation. Lancet 379: 1749-1761, 2012.

3. Perera C, Jhanji V, Lamoureux E, Pollock G, Favilla I and Vajpayee RB: Clinical presentation, risk factors and treatment outcomes of first allograft rejection after penetrating keratoplasty in early and late postoperative period. Eye (Lond) 26: 711-717, 2012

4. Song J and Huang YF: Characteristics of corneal endothelium during allograft rejection after corneal transplantation. Zhonghua Yan Ke Za Zhi 47: 281-284, 2011 (In Chinese)

5. Lowe MT, Keane MC, Coster DJ and Williams KA: The outcome of corneal transplantation in infants, children, and adolescents. Ophthalmology 118: 492-427, 2011.

6. Chen X, Zhao S, Tang X, Ge H and Liu P: Neutralization of mouse interleukin-17 bioactivity inhibits corneal allograft rejection. Mol Vis 17: 2148-2156, 2011.

7. Hegde $\mathrm{S}$ and Niederkorn JY: The role of cytotoxic T lymphocytes in corneal allograft rejection. Invest Ophthalmol Vis Sci 41: 3341-3347, 2000.

8. Shi WY and Xie LX: The corneal allograft rejection features in CD4 and CD8 knock-out mice. Zhonghua Yan Ke Za Zhi 41: 350-354, 2005 (In Chinese).
9. Jessup CF, Brereton HM, Sykes PJ, Thiel MA, Coster DJ and Williams KA: Local gene transfer to modulate rat corneal allograft rejection. Invest Ophthalmol Vis Sci 46: 1675-1681, 2005.

10. Wang DJ, Guo HL, Huang YF, Chen GJ, Zhang H and Li Y: Effects of a new immunodepressant $\mathbf{J} 2$ on lymphocytic secretion of interleukin 10 and interferon gamma in mice after corneal allograft. Journal of Clinical Rehabilitative Tissue Engineering Research 31: 5797-5800, 2011.

11. Masli S, Turpie B, Hecker KH and Streilein JW: Expression of thrombospondin in TGF $\beta$-treated APCs and its relevance to their immune deviation-promoting properties. J Immunol 168: 2264-2273, 2002

12. Okamoto S, Hara Y and Streilein JW: Induction of anterior chamber-associated immune deviation with lymphoreticular allogeneic cells. Transplantation 59: 377-381, 1995.

13. Sano Y, Okamoto S and Streilein JW: Induction of donor-specific ACAID can prolong orthotopic corneal allograft survival in "high-risk" eyes. Curr Eye Res 16: 1171-1174, 1997.

14. Tiao MM, Lu L, Huang LT, et al: Cross-tolerance of recipient-derived transforming growth factor-beta dendritic cells. Transplant Proc 39: 281-282, 2007.

15. Yan F, Cai L, Hui YN, Wang YS and Meng H: Suppression effects of TGF 32 -DC on corneal allograft rejection. Guoji Yanke Zazhi 2: 346-349, 2007 (In Chinese).

16. Ezzelarab M and Thomson AW: Tolerogenic dendritic cells and their role in transplantation. Semin Immunol 23: 252-263, 2011.

17. Wang T, Xu L, Li H, et al: Immature $\mathrm{CD}^{+}$dendritic cells conditioned with donor kidney antigen prolong renal allograft survival in rats. Chin Med J (Engl) 125: 2530-2537, 2012

18. Liu WH, Liu JJ, Wu J, et al: Novel mechanism of inhibition of dendritic cells maturation by mesenchymal stem cells via interleukin-10 and the JAK1/STAT3 signaling pathway. PLoS One 8: e55487, 2013

19. Li B and Hong J: Effects of topically administered rapamycin on cytokine expression after penetrating keratoplasty in rats. Chinese Ophthalmic Research 25: 850-853, 2007.

20. van Kooten C, Lombardi G, Gelderman KA, et al: Dendritic cells as a tool to induce transplantation tolerance: obstacles and opportunities. Transplantation 91: 2-7, 2011.

21. Han B and Hu YH: Inhibitory mechanism of CTLA4Ig-transfected DC in corneal transplantation. Chinese Ophthalmic Research 25: 347-350, 2007.

22. Ouyang J, Fan C, Wen D, et al: Donor antigen-loaded IKK2dn gene-modified dendritic cells prolong allograft survival. Scand J Immunol 71: 336-344, 2010.

23. Qu XY, Wang Y and Qin CH: Effects of U0126 on the process of immature dendritic cells inducing naive $\mathrm{CD}^{+} \mathrm{T}$ cells to differentiate to Treg cells in vitro. The Journal of Practical Medicine 26: 4476-4479, 2010

24. Yang S, Li W, Liu W, et al: IL-10 gene modified dendritic cells induced antigen-specific tolerance in experimental autoimmune myocarditis. Clin Immunol 121: 63-73, 2006.

25. Kushwah R, Oliver JR, Duan R, Zhang L, Keshavjee S and Hu J: Induction of immunological tolerance to adenoviral vectors by using a novel dendritic cell-based strategy. J Virol 86: 3422-3435, 2012.

26. Penna $G$ and Adorini L: 1 Alpha,25-dihydroxyvitamin $\mathrm{D}_{3}$ inhibits differentiation, maturation, activation, and survival of dendritic cells leading to impaired alloreactive T cell activation. J Immunol 164: 2405-2411, 2000 . 